\title{
Article
}

\section{Beyond intimate partner relationships: utilising domestic homicide reviews to prevent adult family domestic homicide}

Bracewell, Kelly, Jones, Cassandra, Haines-Delmont, Alina, Craig, Elaine, Duxbury, Joy and Chantler, Khatidja

Available at https://clok.uclan.ac.uk/39716/

Bracewell, Kelly orcid iconORCID: 0000-0003-4635-7489, Jones, Cassandra, Haines-Delmont, Alina, Craig, Elaine, Duxbury, Joy and Chantler, Khatidja (2021) Beyond intimate partner relationships: utilising domestic homicide reviews to prevent adult family domestic homicide. Journal of Gender-Based Violence. ISSN 2398-6808

It is advisable to refer to the publisher's version if you intend to cite from the work. http://dx.doi.org/10.1332/239868021×16316184865237

For more information about UCLan's research in this area go to

http://www.uclan.ac.uk/researchgroups/ and search for <name of research Group>.

For information about Research generally at UCLan please go to http://www.uclan.ac.uk/research/

All outputs in CLoK are protected by Intellectual Property Rights law, including Copyright law. Copyright, IPR and Moral Rights for the works on this site are retained by the individual authors and/or other copyright owners. Terms and conditions for use of this material are defined in the policies page. 


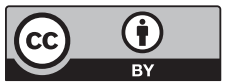

\title{
article
}

\section{Beyond intimate partner relationships: utilising domestic homicide reviews to prevent adult family domestic homicide}

\author{
Kelly Bracewell, kbracewell1@uclan.ac.uk \\ The University of Central Lancashire, UK \\ Cassandra Jones, cassandra.jones@winchester.ac.uk \\ The University of Winchester, UK \\ Alina Haines-Delmont, A.Haines@mmu.ac.uk \\ Elaine Craig, E.Craig@mmu.ac.uk \\ Joy Duxbury, J.Duxbury@mmu.ac.uk \\ Khatidja Chantler, K.Chantler@mmu.ac.uk \\ Manchester Metropolitan University, UK
}

Increasing evidence documents domestic violence and abuse (DVA) and domestic homicide of adults killed by a relative in non-intimate partner relationships. Most literature focuses on intimate partner violence and homicide, yet non-intimate partner homicides form a substantial but neglected minority of domestic homicides. This article addresses this gap by presenting an analysis from 66 domestic homicide reviews (DHRs) in England and Wales where the victim and perpetrator were related, such as parent and adult child. Intimate partner homicides are excluded. These 66 DHRs were a sub-sample drawn from a larger study examining 317 DHRs in England and Wales.

The article contributes towards greater understanding of the prevalence, context and characteristics of adult family homicide (AFH). Analysis revealed five interlinked precursors to $\mathrm{AFH}$ : mental health and substance/alcohol misuse, criminal history, childhood trauma, economic factors and care dynamics. Findings indicate that, given their contact with both victims and perpetrators, criminal justice agencies, adult social care and health agencies, particularly mental health services, are ideally placed to identify important risk and contextual factors. Understanding of DVA needs to extend to include adult family violence. Risk assessments need to be cognisant of the complex dynamics of $\mathrm{AFH}$ and must consider social-structural and relational-contextual factors.

Key words adult family domestic homicide $\cdot$ domestic violence $\cdot$ mental health • childhood trauma $\cdot$ care dynamics 


\section{Key messages}

1. Understanding of domestic violence and abuse needs to include adult family violence.

2. Risks and dynamics of adult family homicide are complex and must consider social-structural and relational-contextual factors.

3. Criminal justice agencies, social care, substance misuse and mental health services provide opportunities for prevention.

To cite this article: Bracewell, K. and Jones, C. Haines-Delmont, A. Craig, E. Duxbury, J. Chantler, K. (2021) Beyond intimate partner relationships: utilising domestic homicide reviews to prevent adult family domestic homicide, Journal of Gender-Based Violence, vol XX, no XX, 1-16, DOI: $10.1332 / 239868021 \times 16316184865237$

\section{Introduction}

Globally, women are more likely to be killed by a partner, ex-partner or a family member than men (UNODC, 2018; ONS, 2020). In England and Wales, almost half (48\%) of adult female homicide victims constituted a domestic homicide (ONS, 2020) and suspects were usually a male partner/ex-partner followed by other family members.

Domestic Violence Fatality Reviews/Domestic Homicide Reviews (DVFRs/ DHRs), were introduced in the 1990s in the US. In England and Wales, they are conducted when a person aged over 16 dies from violence, abuse or neglect by a relative, intimate partner or member of the same household (Home Office, 2016). DHRs became a statutory requirement for Community Safety Partnerships/ Public Services Boards in England and Wales in April 2011, under section 9 of the Domestic Violence, Crime and Victims Act (2004). DHRs aim to identify lessons learned to strengthen responses to domestic violence and abuse (DVA) by making recommendations to improve policy and practice.

The focus of this article is a document analysis (Gross, 2018) of adult family homicide (AFH) DHRs as little is known about the context and nature of these domestic homicides (Holt, 2017).AFH encompasses parricide, fratricide and sororicide. Intimate partner homicides are excluded. Our sample comprises 66 adult family DHRs in England and Wales.

\section{Adult family homicide: prevalence and characteristics}

Increasing evidence documents DVA and homicide of older adults killed by a family member (for example, Benbow et al, 2018). Benbow et al (2018) have highlighted the conflation between adult family violence, intimate partner violence (IPV) and elder abuse. However, studies consistently show that AFH is gendered (Holt 2017; Bows, 2019), with the most common form of AFH being parricide. Existing international research suggests that perpetrators are more likely to be the son or grandson of the victim who is usually female (Cussen and Bryant, 2015; Sharp-Jeffs and Kelly, 2016). Even where the victim is male, most perpetrators were also male (Bows, 2019). Victims of AFH are often older than intimate partner homicide victims (Benbow et al, 2018; Chantler et al, 2020). Older men are at lower risk than women of domestic homicide and are more likely to be murdered by a son/grandson than their spouse/ 
partner (Heide, 2014; Bows, 2019; Chantler et al, 2020). In these cases men are more at risk from other men.

Theories of parricide have been dominated by US research, particularly Heide's (1992) 'typology of parricide'. This focuses on perpetrator psychopathology and suggests that "parricide is committed by three types of individuals: (1) the severely abused child (2) the severely mentally ill child and (3) the dangerously antisocial child' (Heide, 1992: 6). Subsequent research has examined the role of mental illness and parricide (for example, Heide, 2013). Holt (2017) advocates for parricide discourse to move away from psychopathology theories, which individualise and de-contextualise incidents, towards exploring continuums of violence within the family. Sources of conflict shaped by wider social, political, developmental and contextual factors (see Holt, 2017; Flynn et al, 2020; Bojanić et al, 2020) such as substance misuse, financial issues, criminal history and living with the victim might also be important.

Current UK risk assessments focus on IPV (for example, pregnancy, young children) and fail to capture the different dynamics of adult family violence (Sharp-Jeffs and Kelly, 2016; Bows, 2019) or a life-course perspective (Chantler et al, 2020). Further information is needed about the overall prevalence, trends, context and characteristics of adult family violence. This article addresses this gap by contributing towards greater understanding of AFH to aid policymakers and practitioners to identify and strengthen responses to adult family violence.

\section{Method}

Publicly available DHRs from local Community Safety Partnership websites in England and Wales $(n=317)$ were collected in collaboration with the King's College London. This article is based on an analysis of a sub-sample of these DHRs $(n=66)$ where the victim and perpetrator were family members aged over 16. These homicides occurred between 2011 and 2016 with their corresponding DHRs published between 2012 and 2018. Ethical approval was not required due to their public availability and anonymisation. Drawing on existing literature, consultation with the expert advisory group and our pilot study (see Chantler et al, 2020), templates were refined to systematically extract quantitative and qualitative data.

A thematic document analysis (Gross, 2018) was undertaken by the lead author (KB) and Principal Investigator $(\mathrm{KC})$ in collaboration with team members according to areas of expertise. We triangulated the quantitative data from the adult family DHRs to guard against bias and contextualise the qualitative data analysis, while referring to existing research. The qualitative template captured key components of DHRs including family configuration, relationship, service involvement, safeguarding, good practice and recommendations. The populated templates were exported into NVivo12 to organise, classify and analyse the data. To enhance validity and rigour, interpretative coding was completed manually alongside automated coding to provide comparison and check researcher interpretation and organisation. Information, classifications, and trends were cross-examined using query functions which enabled the research team to conceptualise, examine relationships and interrogate the data. We built code structures which supported emerging categories and explored meaning and complexity through the creation of matrices.

Quantitative variables were extracted from the 66 DHRS and coded into SPSS26 (by CJ supported by JD, AH, EC) capturing information on: victim and perpetrator 
characteristics; victim-perpetrator relationships, including history of DVA; risk factors for DVA and homicide; and service engagement. Mental health was categorised according to the main disorder types within the DSM-IV-TR (American Psychiatric Association, 2000). Other risk factors (that is, substance use, financial difficulties, childhood trauma, caring roles) were coded as ' 1 Present' if they were described in the DHR. Descriptive analyses presented the number of victims or perpetrators who were described in DHR documents as having a risk factor.

\section{Characteristics of victims and perpetrators}

Victim information presented here describes the primary victim, as determined by DHR authors. More than half of victims were women $(n=37 ; 56.1 \%)$ and nearly all perpetrators were men $(n=60 ; 90.9 \%)$.Victims were aged 17 to 95, with an average age of 60.7 years $(S D=18.6)$. Perpetrators tended to be younger than victims (age range: $15-73$ years), with an average age of $33.0(S D=11.6)$. For both victims and perpetrators, there was substantial missing data for ethnicity, 40.9\% $(n=27)$ and $42.4 \%(n=28)$, respectively, limiting analyses. The most common type of victim-perpetrator relationship was parental $(n=48 ; 72.7 \%)$ followed by sibling $(n=9 ; 12.6 \%)$ and extended family $(n=7 ; 10.6 \%)$, most often a grandparent $(n=5)$. Two perpetrators $(3.0 \%)$ had killed their partner's father. Six $(9.1 \%)$ DHRs had two victims.

Table 1 presents a summary of the risk and contextual factors identified.

The relationship between the victim and perpetrator is described in 52 out of 66 DHRs. In our reading, 28 DHRs described the relationship negatively (54\%) and in 18 it can be described as mixed (35\%). Only in six was it described positively (11\%). This is important when considering the themes detailed here given that victim-perpetrator relationships were not considered within the context of DVA.

Table 1: Key risk and contextual factors

\begin{tabular}{|l|c|c|c|c|}
\hline & Victims (N=66) & $\begin{array}{c}\text { Perpetrators } \\
(\mathrm{N}=66)\end{array}$ & Chi-Square & Cramer's V \\
\hline alcohol misuse*** & $20(30.3 \%)$ & $41(62.1 \%)$ & 13.441 & .319 \\
\hline substance misuse*** & $10(15.2 \%)$ & $40(60.6 \%)$ & 28.976 & .469 \\
\hline mental health difficulties*** & $19(28.4 \%)$ & $52(78.8 \%)$ & 33.190 & .501 \\
\hline criminal justice history*** & $17(25.8 \%)$ & $47(71.2 \%)$ & 27.298 & .455 \\
\hline childhood trauma*** & $10(15.2 \%)$ & $34(51.5 \%)$ & 19.636 & .386 \\
\hline child abuse*** & $5(7.6 \%)$ & $30(45.5 \%)$ & 24.300 & .429 \\
\hline Financial issues & $21(31.8 \%)$ & $20(30.3 \%)$ & 0.035 & .016 \\
\hline Physical health problems** & $39(59.1 \%)$ & $21(31.8 \%)$ & 9.900 & .274 \\
\hline caring role & $14(21.2 \%)$ & $16(24.2 \%)$ & 0.173 & .036 \\
\hline
\end{tabular}

Note. Chi-square analyses were conducted to compare the proportion of victims and perpetrators with a risk/contextual factor. For risk and contextual factors with $\mathrm{a}^{*},{ }^{*}$, , or $* * *$, the analyses were statistically significant. For example, (1) significantly more perpetrators misused alcohol $(n=41 ; 62.1 \%)$ than victims $(n=20 ; 30.3 \%)$; (2) significantly more victims $(n=39 ; 59.1 \%)$ had physical health problems than perpetrators $(n=21 ; 31.8 \%)$.

${ }^{*} p<0.05,{ }^{* *} p<0.01,{ }^{* * *} p<0.001$ 


\section{Findings}

Five interlinked themes were identified as key factors in the perpetration of AFH: mental health and substances/alcohol, a history of criminal behaviour, childhood trauma, financial issues and the dynamics of care. Recommendations from these DHRs are also considered.

\section{Theme 1: mental health and substance/alcohol misuse}

Perpetrators' mental health was a dominant feature and is prominent across the wider themes discussed: $53.0 \%$ of perpetrators $(n=35)$ were reported to have diagnosed mental health problems, most frequently psychotic disorders and mood disorders such as depression. In comparison, a smaller proportion of victims were reported to have mental health problems $(9.1 \%, \mathrm{n}=6)$, presented in Figure 1.

A common risk factor among perpetrators was alcohol misuse $(62.1 \%, n=41 ; 38$ were men) and substance misuse (60.6\%,n=40;39 men, 1 transwoman). This was less prevalent among victims, with $30.3 \%$ ( $n=20 ; 17$ of whom were men) described as misusing alcohol and $15.2 \%(n=10 ; 9$ were male) misusing substances. Nearly half of perpetrators $(48.5 \% ; n=32)$ were described as misusing both alcohol and substances compared to $13.6 \%(n=9)$ of victims. Several DHRs reported mental health and substance misuse (including alcohol) comorbidity issues, especially among perpetrators (39.4\%; $\mathrm{n}=26)$. Additionally, perpetrators were reported to lead a chaotic lifestyle; including sleeping rough and having a history of offending behaviour.

Nearly all perpetrators with mental health difficulties received support for mental health $(88.5 \% ; n=46)$ and physical health $(86.5 \% ; n=45)$ yet challenges for services in engaging with them were highlighted. Often DHRs described perpetrators as

Figure 1: Proportion of victims and perpetrators with a mental health diagnosis

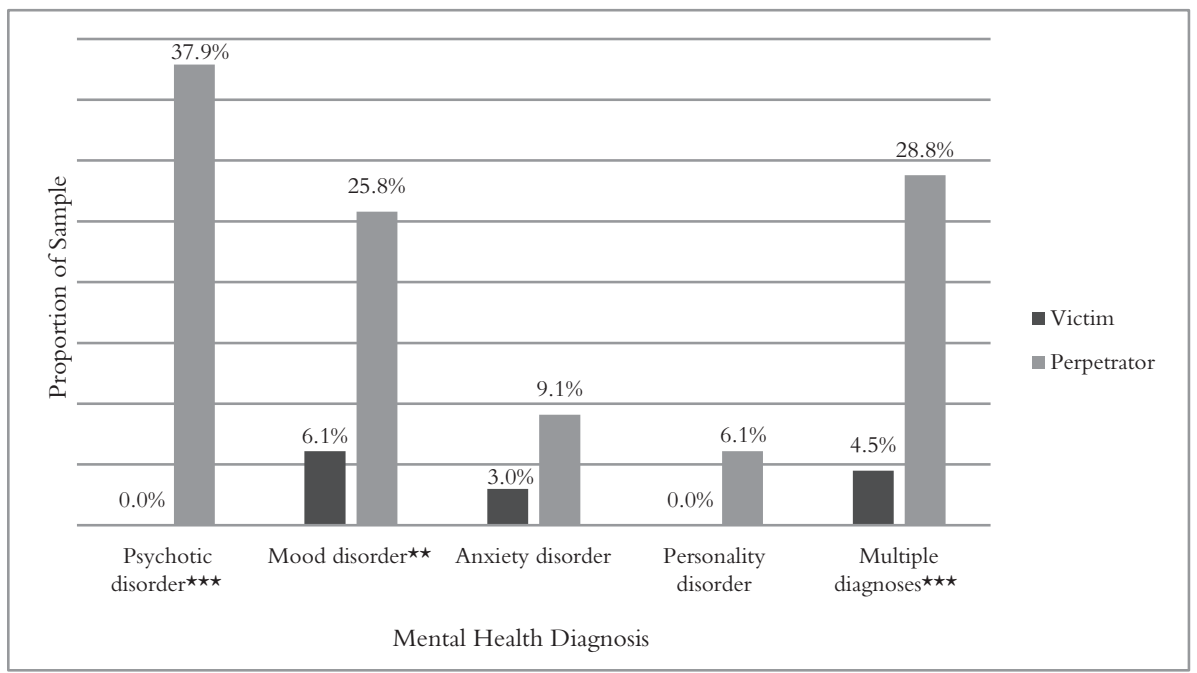

Note. Chi-square analyses were conducted to compare the proportion of victims and perpetrators with a mental health diagnosis. For a mental health diagnosis with $\mathrm{a} *, * *$, or $* * *$, the analyses were statistically significant. For example, significantly more perpetrators $(n=25 ; 37.9 \%)$ were diagnosed with a psychotic disorder than victims $(n=0 ; 0 \%)$.

${ }^{*} p<0.05,{ }^{* *} p<0.01,{ }^{* * *} p<0.001$ 
missing appointments or masking symptoms. For example, DHR068 states that mental health services assumed the victim cared for the perpetrator and assisted with his medication. The DHR identified that this was inaccurate and in fact the perpetrator was controlling of his mother. Wider family members were not involved in care planning processes and the victim considered that her son (the perpetrator) required urgent admission to hospital. A bed was made available a few days later but professionals were unable to make contact. Police forced entry to the property following family concerns; they found the victim deceased and the perpetrator in the house. Disengagement with mental health services, changes in behaviour towards his mother, social life and personal hygiene were marked in the report as key changes in his behaviour in the period prior to the homicide.

Some DHRs reported that relatives attempted to get support for their adult children as part of their 'carer' role and this is discussed later. Adult family DHRs highlight the need for professional support for those caring for people with mental health problems. Some DHRs considered the stigma of mental health as a barrier to accessing support or service engagement. For example, DHR275 noted that the perpetrator appeared to disguise his symptoms, sometimes at his mother's (victim's) request and explicitly identifies the mother's mistrust of services. Her daughter felt accessible information (in multilingual form) about mental health interventions and the rights of mentally vulnerable individuals may have alleviated her mother's fears of services.

\section{Theme 2: criminal behaviour}

Most perpetrators ( $\mathrm{n}=47,71.2 \%$; only two of whom were women) and some victims $(25.8 \%, n=17 ; 14$ of whom were men) had a history of criminal behaviour ranging from motoring offences, shoplifting, criminal damage, firearms offences, violence and burglary to DVA, sexual assault and harassment. For 16 cases $(24.2 \%)$, both the victim and the perpetrator had a criminal offence history. On some occasions the DHRs noted police involvement due to mental health issues.

Almost half of perpetrators $(n=32,48.5 \%)$ had a history of criminal offences related to DVA, frequently of an intimate partner. Of this group, 25 (78.1\%) also had alcohol misuse problems and $24(75.0 \%)$ had substance misuse problems. While DVA was recorded against other family members, the DHR recommendations indicate that DVA was not always recognised outside of intimate partner relationships and so this figure might be an underestimate.

Perpetrators' involvement with the criminal justice system was a prominent theme. Police involvement was noted regarding 50 out of 66 (75.8\%) perpetrators. In two DHRs where the perpetrator killed their sibling there was a history of DVA. For example, in DHR250 both brothers had a history of DVA towards their intimate partners, violence towards each other and violence in their parents' home. Agencies focused on IPV which marginalised the DVA between the brothers. DHR250 details that the volume of call outs and referrals meant that the response was not always consistent with expected practice, particularly regarding risk assessment and looking beyond the immediate incident. Similarly, in other cases, DVA was recorded but appeared to be treated as isolated incidents.

Criminal justice involvement included Probation services for nearly one third $(n=21,31.8 \%)$ of perpetrators. Most of this group also had intersecting mental health 
and substance misuse issues. These perpetrators were usually involved with other agencies such as mental health services or children's social care, but multi-agency working was poor. To illustrate, in DHR271 probation were unaware that they were supervising members of the same family despite information from other relatives. Concerns were highlighted around the failure to adopt an investigative approach by sharing information or carrying out checks with other agencies. Opportunities were sometimes missed by probation which would have helped to identify wider risk beyond the intimate partner relationship.

\section{Theme 3: childhood trauma}

DHRs do not have a standardised 'looking back' timeline, however some comments are made about perpetrators' childhoods, particularly about trauma in childhood. Perpetrators' childhoods were included in half of DHRs $(n=34,51.5 \%)$. In contrast, the DHRs included little about the victims' childhood ( $\mathrm{n}=10,15.2 \%)$. Two key types of perpetrator childhood trauma were evident: i) childhood abuse $(n=30 ; 45.5 \%)$ (including DVA, sexual abuse or neglect) and ii) death of a parent $(n=8 ; 12.1 \%)$. In some cases, 'disputes', 'turbulence', or 'parental conflict' is mentioned but not defined as DVA. All 30 homicide perpetrators who had experienced childhood abuse were male. In 13 cases their abuse had been committed by the victim, nine of whom were male that is, fathers were murdered by their son. To illustrate, in DHR017, where a son killed his father, the son was exposed to DVA, physical abuse by his father, excessive drinking by both parents and subsequent neglect. His parents divorced due to his father's DVA and by his early teens, the young person is described as out of control and engaging in serious criminal activity. He was taken into local authority care and frequently ran away. At 21, he moved in with his father and was convicted of actual bodily harm and affray against his father. Both men had serious alcohol problems and his father was also violent towards him.

Some perpetrators experienced bereavement as a child, usually of their father. In three cases the perpetrator's father had been murdered (DHR021, DHR090, DHR226) and in DHR173 the father had committed suicide when the perpetrator was a child. In DHR271 the victim and perpetrator lost their father when they were children due to alcohol related problems. In DHR010 the perpetrator witnessed his father's death from a heart attack at the age of 10. Subsequently, he went to live with his grandmother as his mother was struggling to cope following her husband's death. As an adult, he moved to live in the same block of flats as his mother as his mother's carer and subsequently killed her.

A further risk factor identified was the connection between childhood trauma for perpetrators with mental health difficulties. Out of 52 perpetrators with a history of mental health difficulties, 28 experienced abuse or trauma as a child compared to five out of 19 victims with a history of mental health difficulties. In DHR018 the perpetrator experienced mental health difficulties, but as a child had experienced her mother's alcohol dependency, mental health issues, physical and psychological abuse and her brother being removed into care. In DHR201, the perpetrator's father was abusive with alcohol problems and mental health issues, while his mother also had mental health issues. The report states that the perpetrator had been abused by his father (the victim) as a child and highlights the failure to investigate the extent 
of the abuse, whether he was a DVA victim at the time of the homicide or if DVA contributed to a mental health condition. The judge concluded that this was 'a slow burn of loss of control, following accumulative abuse... against the background of mental health' (p 8).

While many DHRs discussed the need for historic risk factors such as childhood trauma, DHRs do not tend to make recommendations to attend to children's trauma at the appropriate moment. This signifies a gap between wider learning and current practice and is detailed in the discussion.

\section{Theme 4: financial issues}

Financial pressures and economic abuse while not always explicitly stated in the DHRs, were identified in our analysis. Where employment status was listed $(n=36) 26$ perpetrators were unemployed (72.2\%). In almost a third of cases where employment was recorded, victims were retired $(31.6 \%, \mathrm{n}=12)$. Perpetrators with a history of unemployment $(45.5 \%, \mathrm{n}=30)$ was double that of victims $(19.7 \%, \mathrm{n}=13)$. Housing need can also be a proxy for financial pressures and most perpetrators (46 cases, 69.7\%) lived with the victim - not necessarily by choice. Other perpetrators lived very close to the victim and many had experienced a breakdown in their intimatepartner relationship, a potential contributory factor to financial stress.

Within the DHRs 20 (29.9\%) perpetrators and 21 victims (31.3\%) were directly described as experiencing financial problems. Ten cases described both the victim and perpetrator as experiencing financial issues; with at least four cases acknowledging them as an escalating factor. It is likely that financial issues were a potential stressor, most frequently where the perpetrator was reliant on the family. However, in DHR040 the perpetrator had helped his parents following bankruptcy, including buying the family home so that they could continue to live there. In this case the stressor might be linked to having to provide for others.

Financial/economic abuse of victims was reported in seven DHRs. There were no instances whereby the victim was described as financially abusing the perpetrator. Perpetrators were described as stealing from or continuously requesting money from their victim. On occasion victims were seen to 'give' money to perpetrators directly or because the perpetrator had access to their bank account. For example, in DHR 055 the victim had won a large sum of money but by the time of the homicide she was receiving financial aid from her local church. The DHR describes her as 'enabling' her son (the perpetrator) to buy drugs. In DHR084 the father (victim) inherited some money. Large sums were taken by various family members and his account became overdrawn. He lived with the perpetrator and his girlfriend in a one bedroom flat. He was described as frail, with physical health needs but did not meet residential care criteria. The perpetrator called children's social care at seven years old asking to be removed from the family home due to DVA from his father. The DHR indicates that practitioners did not recognise the victim's 'vulnerability' related to the potential for retaliation by the perpetrator for the years of abuse experienced at his father's hands.

Dynamics of care is discussed next but of the 16 perpetrators who were carers, half $(n=8)$ had financial problems compared to two of the 15 victims who were carers. Most perpetrators within a caring dyad were unemployed $(n=9,56.3 \%), 62.5 \%(n=10)$ 
had housing needs (that is, inconsistent or temporary housing) and in 14 out of 16 cases $(87.5 \%)$ the perpetrator lived with the victim.

\section{Theme 5: dynamics of care}

'Caring' relationships featured in 30 DHRs. In 14 cases the victim was a carer for the perpetrator $(n=10)$ or someone else $(n=4)$ and in 16 cases the perpetrator was a carer for the victim $(n=14)$ or someone else $(n=2)$. Most cases comprise parricide. Seven of the 10 victims who were carers were women and nine of the 14 perpetrators who were carers were men.

More than half of victims had physical health problems $(59.1 \%, \mathrm{n}=39)$ in comparison to perpetrators $(31.8 \%, \mathrm{n}=21)$. While this may be linked to the older age range of victims it is a vulnerability factor which may increase the need for in/formal care or reliance on relatives. In some DHRs caring was highly ambiguous where the 'carer' (normally the perpetrator) self-identified as such although they appeared to have substantial care, mental health needs or substance misuse issues. Such relationships were characterised by elements not synonymous with typical 'caring' relationships. For instance, perpetrators stole money from their victims or subjected them to sexual/ physical abuse. DHRs highlighted that professionals failed to recognise that a close relative (for example, an adult child) can cause harm. Mostly, victim-perpetrator relationships were never considered within the context of DVA and therefore never triggered a risk assessment such as the Domestic Abuse, Stalking and Honour Based Violence (DASH) Risk Identification Check list, referral to Multi-Agency Risk Assessment Conferences (MARACs), adult or mental health safeguarding alert.

In all but one case where the victim was a carer the perpetrator had mental health issues $(90 \%, n=9)$. Carers' views were absent from mental health assessments and it was difficult to access treatment for their relative. Professionals did not sufficiently consider a carer's ability to manage mental health problems, medication and service engagement. In DHR085, for example, the perpetrator's mother and grandparents repeatedly requested that the perpetrator remain in hospital as they felt he was too unwell to be discharged. Instead he was discharged into the care of his aged grandparents and relatives were expected to monitor his medication. In DHR221 the family were concerned that they did not have a point of contact with mental health services. They had no awareness of carers' information packs, and this was not mentioned in the mental health trust review. Where the perpetrator was the carer, mental health was also prominent.

Co-dependency was evident and raises key lessons about the nature of care, 'carers' suitability and adult and mental health safeguarding. In these DHRs both members of the dyad had care and support needs. For instance, in DHR095, a son battered his disabled mother to death.This complex case had multiple intersecting issues spanning childhood trauma, criminal history, financial problems, physical health issues and problematic substance use. They lived together with mutual caring responsibilities. However, the power within the relationship rested with the son whom services described as 'difficult' and 'aggressive'. The police recorded over 150 incidents with over 60 reported as DVA and flagged as high risk because of the perpetrator's alcohol and substance misuse. Information was not shared with other agencies. No adult safeguarding or carer's assessment was undertaken for either party. 


\section{Recommendations and learning from adult family DHRs}

Over 600 recommendations were made across the 66 adult family DHRs. While recommendations are specific to each agency and local authority involved, many commonalities were found. Many of these centred around well-rehearsed recommendations of increasing training and improving multi-agency working and information sharing. DHRs reinforced the need for greater coordination between those supporting and caring for the perpetrator and those responsible for assessing support for the victim. Over half of DHRs $(n=38,58 \%)$ identified the need for specialist mandatory training for frontline practitioners across key agencies focusing on adult family violence as a form of DVA and contributory risk factors. Training or engagement around parental abuse was limited, as was specialist service provision for older children who might be experiencing or perpetrating DVA.

DHRs reported a need for enhanced professional curiosity. Often questions were not asked, reports not investigated and information remained unchecked or overlooked. Curiosity should include exploration of the victim-perpetrator relationship. There were also concerns around the degree to which professionals were supervised to foster a culture of professional curiosity. Improved risk assessment was recommended in at least 40 DHRs. These highlight the importance of practitioners having a nuanced understanding of risk, including recognising that carers of close relatives can be abusive. Some DHRs questioned the appropriateness of the DASH risk assessment for adult family violence. Other DHRs recommended that assessments for specialist mental health services included significant others involved in the life of the service user. Sometimes risk to professionals was recognised but not extended to relatives. Professionals failed to recognise the importance of historic abuse, DVA over an extended period or the dynamics when both the victim and perpetrator have displayed mutual violence. DHRs emphasised that risk assessments should be regularly reviewed and considered a fluid 'ongoing' process.

\section{Discussion}

Our findings confirm that these homicides are gendered (Sharp-Jeffs and Kelly, 2016; Holt, 2017) but that there are more male victims of AFH compared to intimate partner homicide (Bows, 2019). The analysis identified a range of key intersecting issues including mental health, substance use, lack of service engagement, criminal justice involvement, childhood trauma, financial issues and carer roles. DHR recommendations highlighted important areas for agencies and local authorities to address, including training, professional curiosity, risk assessment, multi-agency working and information sharing. These DHRs showed little change with similar recommendations made across time and geographical location. It is necessary, but not sufficient, for individual local authorities to try to change systemic obstacles. This requires adequate resourcing to conduct and evaluate DHRs as well as to implement recommendations (Jones et al, under review; Montique, 2020).

Research suggests that perpetrators are more likely to have a serious mental illness (Heide, 2017; Bojanić et al, 2020). Heide (2017) suggests that mental illness is found in parricide offenders, but that it can only be considered a direct reason for homicide in the severely mentally ill offender. However, our findings indicate that less enduring mental health problems are likely to have been a contributory factor (see also Chantler et al, 2020). While Holt (2017) exercises caution about mental illness 
being an explanation for parricide, findings highlight the centrality of mental ill-health in AFH while being attentive to social-structural and relational-contextual factors.

Caregivers (particularly mothers) who live with patients, are more likely than strangers to be the targets of homicide (for example, Copeland and Heilemann, 2008; Sharp-Jeffs and Kelly, 2016). This is significant considering up to $90 \%$ of people with a mental health difficulty live with their families (Lauber et al, 2003). Most perpetrators struggling with mental health issues in our sample had contact with mental health support. Therefore, procedures and monitoring arrangements to ensure that specialist mental health services work collaboratively with families to better support the service user are paramount. This may be beneficial where services encounter engagement difficulties. Findings also revealed substance use and co-morbidity with mental health problems featured more frequently for perpetrators compared to victims, confirming recent evidence (Oliver and Jaffe, 2018). Our findings indicate that more work is needed to address barriers to help-seeking and service engagement.

Perpetrators' involvement with the police and probation were common, which suggests that they have a key role to play in identifying risks of homicide. The Association of Chief Police Officers recommended the use of the DASH risk assessment. However, this was intended to assess risk in the context of IPV, not adult family violence. Similarly, probation services use the Spousal Assault Risk Assessment (SARA), a validated tool for assessing risk of IPV (NOMS, 2016). Prior research on AFH showed that the risk factors may differ from intimate partner homicide (for example, Benbow et al, 2018; Bows, 2019; Chantler et al, 2020), indicating that current risk assessment tools need to be updated to include adult family violence or a specific tool needs to be developed. These changes would aid criminal justice agencies in making their practice more congruent with the Home Office's (2016) definition of domestic homicide which includes the death of all persons over the age of 16 who were killed by a relative.

Childhood abuse features in the parricide cases and this is supported by Heide's (1992) typology of parricide. Perpetrators who had experienced abuse or trauma appeared to receive little formal support for their experiences at the time they occurred. Research indicates that for some children this has long-term consequences and impacts on their later mental or physical health (Alisic, 2017; Dye, 2018). There is therefore an identified need for therapeutic work with children exposed to trauma (Alisic et al, 2017; Stanley et al, 2019). DVA was frequently found across the sample where childhood experiences were disclosed and yet specialist services working with children experiencing DVA remain overstretched, underfunded and unsustainable (Reif et al, 2020). DHR panels should develop recommendations to improve existing service provision for children experiencing trauma based on their learning of historical trauma revealed in the DHRs. These recommendations have significant implications for policymakers.

Social-structural factors such as financial stressors were a key issue. There is growing understanding of economic abuse as a hidden form of IPV (for example, Sharp-Jeffs, 2015; Eriksson and Ulmestig, 2017; Postmus et al, 2018). The Domestic Abuse Act 2021 recognises economic abuse for the first time in law and is defined as any behaviour that has a substantial and adverse effect on an individual's ability to acquire, use or maintain money or other property; or obtain goods or services. The literature makes a distinction between financial and economic abuse (Sharp-Jeffs, 2015; Postmus et al, 2018). Financial abuse is restricted to one partner accessing 
money and finances of the other whereas economic abuse involves control through restriction, exploitation and sabotage for example, sabotaging someone's ability to work (Postmus et al, 2018). These concepts have been developed in relation to IPV but are useful in understanding adult family violence. For adult family violence economic abuse may be difficult to identify, particularly given complex dynamics, historic conflict or where the perpetrator feels entitled to the victim's assets. In our sample many perpetrators were unemployed or lived with their relatives and were likely to have been dependent on their family for financial reasons and/or care needs. A combination of perpetrator unemployment and victim retirement might mean that victims are more isolated and available to their perpetrator. Economic necessity, feelings of familial obligation, care dynamics and a close relationship might increase vulnerability. Previous literature highlights aspects related to power relations such as dependence of the relative/perpetrator on the caregiver, unemployment, and high expressed emotion as risk factors for violence (Hsu and Tu, 2013; Benbow et al, 2018).

Many of the relationships between the perpetrator and victim were based on 'care' and is an important relational-contextual factor. Often, the carer had not received a formal assessment but performed many of the tasks of a carer. Under the Care Act 2014, a person supporting another on a regular basis is entitled to a carer's assessment which focuses on the person's needs and wellbeing (including being safe). Assessments provide the opportunity of supporting both people, but also the identification of and intervention in DVA where appropriate. Our evidence indicates that this appears to be a missed opportunity for prevention of homicide. Some of the care provided was clearly problematic where 'carers' themselves had serious and long-standing alcohol/substance misuse issues. Moreover, professionals may sometimes place undue confidence in the capacity of relatives to act as carers (ADAAS, 2011). Providing appropriate assessment, information, support and interventions for caregivers and treating them as equal partners is crucial (MacInnes and Watson, 2002). Researchers have called for a developmental and intersectional approach to the study of parricide, namely, to appraise the association of different societal, familial and clinical factors (Holt and Shon, 2018).

Older relatives might feel guilty that the perpetrator may not manage without their care. Help-seeking by family and friends could be increased if community and professional knowledge about DVA beyond IPV is fostered. Previous literature indicates that some older carers, and those from ethnic minority groups, may be intimidated by organisational behaviours (Department of Health, 2009). Our findings demonstrate the necessity of research into the barriers associated with help-seeking by perpetrators, friends and family, as well as the obstacles for agency referral and timely service provision. Austerity has also affected the availability and delivery of public services amid increasing demand (Devaney, 2019).

Often agencies worked in silo with either victim or perpetrator with an absence of joint risk assessments or multi-agency discussions. DVA was not always identified because frequently agencies focused on a single issue, for example, substance misuse. What is important is that wider contextual and historical risk factors were not consistently included. Questions need to be asked consistently, reports should be investigated thoroughly, and information must be shared adequately to inform risk assessment. Risk to professionals is a strong indication of wider risk to others such as family members. Furthermore, risk assessment requires professional judgement, curiosity and a broader understanding of context which must extend to perpetrators. 
They have greater contact with a range of professionals compared to victims which provides opportunities to undertake (and review) risk assessments with perpetrators rather than only victims. Enhanced training and improved risk assessment tools could facilitate this.

\section{Limitations}

DHRs are not written for research purposes. The quality, consistency and scope across the reviews varies significantly despite statutory guidance. Some CSPs publish only executive summaries or omit large amounts of data, often attributable to maintaining confidentiality.There is often a lack of information regarding basic socio-demographics of victims and perpetrators, such as ethnicity, disability, age or even sex. The Home Office have introduced a demographic template ${ }^{1}$ to complete alongside DHRs - however these are not publicly available and will be unavailable to researchers (personal communication with the Home Office). The template should be open to review and include new domains based on research.

Information about the victim is lacking compared to perpetrator information. While this is partly dependent on family and friends' willingness to participate in the DHR process, it is also incumbent on DHR chairs to engage family and friends (Mullane, 2017). Caregiver factors and information about victim-perpetrator relational dynamics are also often missing. This could be because reports focus on organisational failure of care and managing reputational risk and less so on organisational learning (Cohen, 2013). However, maintaining family and friend involvement helps to counter this by providing in-depth understanding of the victim-perpetrator relationship.

\section{Conclusion}

Utilising DHRs for research purposes has limitations. Nevertheless, there is useful learning at both a local and national level across the themes found within the adult family homicides utilising both social-structural factors such as unemployment, gender/sex, financial difficulties and relational-contextual actors such as care relationships, dependence (on others or substances), and trauma/violence. Given their contact with both victims and perpetrators, criminal justice, adult social care and health agencies are ideally placed to identify important risk and contextual factors. Where agencies address either mental health or substance misuse, for example, they fail to identify DVA. Thus, understanding of DVA needs to be expanded to include adult family violence and reflected in service responses and risk assessment, alongside multi-agency working and information sharing. It is important for professionals to view risk as fluid and consider the range of factors highlighted in this article. This includes violence towards and risk to others (partners, relatives and professionals).

Risk and dynamics relating to AFH are complex and must consider social-structural as well as relational-contextual factors influencing violence. For instance, a key finding is related to mental health. Although perpetrators were known to mental health services, many did not engage. Mental health services need to find creative methods of engaging perpetrators for both their mental health needs as well as enquiring about DVA in partner and other familial relationships.

Our findings have implications for both adult and child social care services. The dynamics of care in AFH are an important yet neglected area of research and practice. 
In England and Wales, the Care Act (2014) provides the remit for addressing the shortfalls related to care identified in this article. The role and status of carers of those with mental or physical illness is a key issue which needs to be reviewed. The impact of childhood trauma should be prioritised within current practice as part of the learning gained from DHRs. The Children's Acts 1989 and 2004 place a legal requirement on services to improve outcomes for children. Finally, the common recommendations and learning from across the DHRs should be shared beyond the level of the immediate local authority to ensure maximum impact of DHRs. Responsibility and resourcing of this should be discussed by the Home Office and Domestic Abuse Commissioner.

\section{Note}

${ }^{1}$ Domestic homicide review: community safety partnership reporting form available at: https://www.gov.uk/government/publications/revised-statutory-guidancefor-the-conduct-of-domestic-homicide-reviews

\section{Funding}

The authors acknowledge the support provided by the Economic and Social Research Council, UK under grant number ES/S005471/1.

\section{Conflict of interest}

The Authors declare that there is no conflict of interest.

\section{References}

ADAAS (2011) Carers and safeguarding adults working together to improve outcomes, https://www.adass.org.uk/adassmedia/stories/Policy\%20Networks/Carers/ Carers\%20and\%20safeguarding\%20document\%20June\%202011.pdf.

Alisic, E., Groot, A., Snetselaar, H., Stroeken, T. and van de Putte, E. (2017) Children bereaved by fatal intimate partner violence: a population-based study into demographics, family characteristics and homicide exposure, Plos One, 12(10): e0183466. doi: 10.1371/journal.pone.0183466

American Psychiatric Association (2000) Diagnostic and Statistical Manual of Mental Disorders, 4th edn, text rev. Washington, DC:American Psychiatric Association.

Benbow, S. M., Bhattacharyya, S. and Kingston, P. (2019) Older adults and violence: An analysis of domestic homicide reviews in England involving adults over 60 years of age. Ageing \& Society, 39(6): 1097-121.

Bojanić, L., Flynn, S., Gianatsi, M., Kapur, N., Appleby, L. and Shaw, J. (2020) The typology of parricide and the role of mental illness: data-driven approach, Aggressive Behavior, 46(6): 516-22.

Bows, H. (2019) Domestic homicide of older people (2010-15): a comparative analysis of intimate-partner homicide and parricide cases in the UK, The British Journal of Social Work, 49(5): 1234-53. doi: 10.1093/bjsw/bcy108

Chantler, K., Robbins, R., Baker,V. and Stanley, N. (2020) Learning from domestic homicide reviews in England and Wales, Health \& Social Care in the Community, 28(2): 485-93.

Cohen, M. (2013) Organisational processes around the investigation of serious events, The Psychiatrist, 37(7): 217-20. doi: 10.1192/pb.bp.113.042697 
Copeland, D. and Heilemann, M.V. (2008) Getting 'to the point': the experience of mothers getting assistance for their adult children who are violent and mentally ill, Nursing Research, 57: 136-43 . doi: 10.1097/01.NNR.0000319500.90240.d3

Cussen, T. and Bryant, W. (2015) Domestic/Family Homicide in Australia, Research in practice no. 38. Canberra: Australian Institute of Criminology, https://www.aic. gov.au/publications/rip/rip38.

Department of Health (2009) Safeguarding adults. a consultation on the review of the 'No Secrets' guidance, https://1x.iriss.org.uk/sites/default/files/resources/ safeguarding\%20adults.pdf.

Devaney, J. (2019) The trouble with thresholds: rationing as a rational choice in child and family social work, Child \& Family Social Work, 24(4): 458-66.

Dye, H. (2018) The impact and Long-term effects of childhood trauma, Journal of Human Behavior in the Social Environment, 28(3): 381-92. doi: 10.1080/10911359.2018.1435328

Eriksson, M. and Ulmestig, R. (2017) 'It's not all about money': toward a more comprehensive understanding of financial abuse in the context of VAW, Journal of Interpersonal Violence, 36(3-4): NP1625-1651NP. doi: 10.1177/0886260517743547.

Flynn, S., Ibrahim, S., Kapur, N., Appleby, L. and Shaw, J. (2020) Mental disorder in people convicted of homicide: long-term national trends in rates and court outcome, The British Journal of Psychiatry, 218(4): 210-16.

Gross, J.M.S. (2018) Document analysis, in B. Frey (ed) The SAGE Encyclopedia of Educational Research, Measurement, and Evaluation, Vol 1-4, Thousand Oaks, CA: SAGE Publications, Inc.

Heide K.M. (1992) Why Kids Kill Parents: Child Abuse and Adolescent Homicide, Columbus, OH: Ohio State University Press/London: SAGE (1995).

Heide K.M. (2013) Understanding Parricide: When Sons and Danghters Kill Parents, Oxford: Oxford University Press.

Heide, K.M. (2014) Patricide and step-patricide victims and offenders: an empirical analysis of US arrest data, International Journal of Offender Therapy and Comparative Criminology, 58(11): 1261-78. doi: 10.1177/0306624X13495168

Heide, K.M. (2017) Parricide Encapsulated. In F. Brookman, E. R. Maguire and M. Maguire (eds.), The Handbook of Homicide (pp. 197-211), Hoboken, NJ: Wiley.

Holt, A. (2017) Parricide in England and Wales (1977-2012): an exploration of offenders, victims, incidents and outcomes, Criminology \& Criminal Justice, 17(5): $568-87$.

Holt, A. and Shon, P.C. (2018) Exploring fatal and non-fatal violence against parents: challenging the orthodoxy of abused adolescent perpetrators, International Journal of Offender Therapy and Comparative Criminology, 62(4): 915-34. doi: 10.1177/0306624X16672444

Home Office (2016) Domestic homicide reviews: key findings from analysis of domestic homicide reviews, https://assets.publishing.service.gov.uk/government/ uploads/system/uploads/attachment_data/file/575232/HO-Domestic-HomicideReview-Analysis-161206.pdf.

Hsu, M.C. and Tu, C.H. (2013) Adult patients with schizophrenia using violence towards their parents: a phenomenological study of views and experiences of violence in parent-child dyads, Journal of Advanced Nursing, 70(2): 336-49. doi: $10.1111 /$ jan.12194 
Jones, C., Bracewell, K., Clegg,A., Stanley, N. and Chantler, K. (under review) Domestic homicide review committees' recommendations and impacts: a systematic review .

Lauber, C., Nordt, C., Falcato, L. and Rossler,W. (2003) Do people recognise mental illness? Factors influencing mental health literacy, European Archives of Psychiatry and Clinical Neuroscience, 253: 248-51 . doi: 10.1007/s00406-003-0439-0

MacInnes, D.L. and Watson, J.P. (2002) The differences in perceived burdens between forensic and non-forensic caregivers of individuals suffering from schizophrenia, Journal of Mental Health, 11(4): 375-88. doi: 10.1080/09638230020023741

Montique, B. (2020) Domestic Homicide Review (DHR) Case Analysis and Review of Local Authorities DHR Process, London: Standing Together, https://www.standingtogether. org.uk/blog-3/london-dhr-case-analysis-and-review-launch-2020.

Mullane, F. (2017) Raising the status of families, friends and community members in reviewing domestic homicides, in T. Brown, D. Tyson and P.F. Arias (eds) When Parents Kill Children, Basingstoke: Palgrave Macmillan, pp 241-57.

NOMS (National Offender Management Services) (2016) NOMS Guidance for working with domestic abuse, https://mappa.justice.gov.uk/connect.ti/MAPPA/ view?objectId=22310629.

Oliver, C.L. and Jaffe, P.G. (2018) Comorbid depression and substance abuse in domestic homicide: missed opportunities in the assessment and management of mental illness in perpetrators, Journal of Interpersonal Violence, 36(11-12): NP6441NP6464. doi: 10.1177/0886260518815140.

ONS (Office for National Statistics) (2020) Homicide in England and Wales: year ending March 2019, Newport: Office for National Statistics, https:// www.ons.gov.uk/peoplepopulationandcommunity/crimeandjustice/articles/ homicideinenglandandwales/yearendingmarch2019.

Postmus, J.L., Hoge, G.L., Breckenridge J., Sharp-Jeffs, N. and Chung, D. (2018) Economic abuse as an invisible form of domestic violence: a multi-country review, Trauma, Violence, \& Abuse 2020,21(2):261-83, doi: doi: 10.1177/1524838018764160.

Reif, K., Jaffe, P., Dawson, M. and Straatman, A.L. (2020). Provision of specialized services for children exposed to domestic violence: barriers encountered inViolence Against Women (VAW) services, Children and Youth Services Review, 109: 104684. doi: 10.1016/j.childyouth.2019.104684

Sharp-Jeffs, N. and Kelly, L. (2016) Domestic Homicide Review (DHR) Case Analysis, London: Standing Together.

Sharp-Jeffs, N. (2015) Money matters. research into the extent and nature of financial abuse within intimate relationships in the UK, http://www.refuge.org.uk/files/ Money-Matters.pdf.

Stanley, N., Chantler, K. and Robbins, R. (2019) Children and domestic homicide, The British Journal of Social Work, 49(1): 59-76. doi: 10.1093/bjsw/bcy024

UNODC (United Nations Office on Drugs and Crime) (2018) Global Study on Homicide: Gender-related Killing of Women and Girls,Vienna: United Nations Office on Drugs and Crime, https://www.unodc.org/documents/data-and-analysis/ GSH2018/GSH18_Gender-related_killing_of_women_and_girls.pdf. 